\title{
Familial primary hypomagnesemia with hypercalciuria and nephrocalcinosis with severe ocular involvement
}

INSERM

\section{Source}

INSERM. (1999). Orphanet: an online rare disease and orphan drug data base. Familial primary hypomagnesemia with hypercalciuria and nephrocalcinosis with severe ocular involvement. ORPHA:2196

Familial primary hypomagnesemia with hypercalciuria and nephrocalcinosis with severe ocular involvement (FHHNCOI) is a form of familial primary hypomagnesemia (FPH, see this term), characterized by excessive magnesium and calcium renal wasting, bilateral nephrocalcinosis, progressive renal failure and severe ocular abnormalities. 